\title{
Dynamic and Static Comparative Analysis on the Cost-Profit of Backyard Hog Production and Scale Hog Production in China
}

\author{
Xiaojuan $\mathrm{Jia}^{1, \mathrm{a}}$, Jianqiang $\mathrm{Li}^{2}{ }^{\text {, }}$ * \\ ${ }^{1}$ College of Management Sichuan Agricultural University Chengdu, China \\ ${ }^{2}$ College of Management Sichuan Agricultural University Chengdu, China
}

\begin{abstract}
This paper uses a combination of dynamic comparison and static comparison to comprehensively compare the cost-profit changes and gaps between backyard hog production and small, medium and large scale production from 2007 to 2018 in China, and discusses the relationship between the cost-profit of hog production and production scales. The purpose is to provide data basis and support for the government to formulate relevant policies, and to provide reference for the transformation of farmers' hog production behavior, so as to further promote the healthy and stable development of the pig industry. The results showed that: (1) the cost of backyard hog production is the highest, and the cost of large-scale production is the lowest, and the cost is inversely proportional to the scale of production; (2) the main incentives for the high cost of backyard hog production are the input of piglets, feed and labor, and The main incentives for the high cost of scale hog production are the input of piglets and feed. Scale hog production saves labor costs more than backyard hog production; (3) The net profit of backyard hog production is the lowest, and the net profit of medium-scale production is the highest. It is not that the larger the scale, the higher the profit; (4) The profit gap between backyard hog production and scale hog production is gradually expanding, and the economic advantages of scale hog production are obvious. Therefore, it is necessary to improve the production technology service system, develop moderately scale production, and improve the level of organization of farmers in order to promote the modernization and transformation of backyard hog production and further enhance the competitiveness of China's pig industry.
\end{abstract}

\section{Introduction}

The pig industry is a traditional Chinese agriculture. The so-called " Pork and grain maintain social stability ", the stable development of the pig industry is directly related to the national economy and people's livelihood. With the advancement of agricultural modernization, problems such as backward backyard hog production technologies, high costs, low feed conversion rates, difficult epidemic prevention, and weak resistance to market risks have become increasingly prominent ${ }^{[1-4]}$. Scholars generally point out that scale hog production is the inevitable trend of the future development of the pig industry [5-6]. However, as a traditional family sideline for thousands of small farmers in China, backyard hog production still exists in large numbers, and its pork production volume can't be ignored in stabilizing the supply of pork in the market [7]. Under the current policy background of promoting the organic connection between small farmer production and modern agricultural development, it is necessary to introduce backyard hog production farmers into the modern scale production track to further promote the development of pig industry in China.

At present, scholars mainly promote the modern development and transformation of farmers' backyard hog production by establishing organizational carriers and reasonable scale production. Yang Yimin \& Luo Xiaowen, Ji Chen et. al proposed that Farmers' Professional Cooperatives are a key way to promote the connection between farmers' hog production and modern hog production ${ }^{[8-9]}$. At the same time, "enterprises + bases + farmers", contract farming, and pig farming community can also promote the modernization and transformation of farmers' hog production [10-13]. However, before discussing the modern development path of farmers' hog production, it is particularly important to understand the current development status of farmers' hog production in real time, and to clarify the actual gap with scale hog production. Cost-benefit is an important manifestation of intuitively reflecting the pros and cons of hog production. In view of this, this paper comprehensively compares the gap between farmers' backyard hog production and small, medium and large scale production based on cost-benefit indicators, clarifies the status quo of the differences and finds the reasons for the differences. The purpose is to provide data basis and support for the government to formulate relevant policies, and to provide reference for the transformation of farmers' hog production behavior, so as to further promote the healthy and stable development of the pig industry.

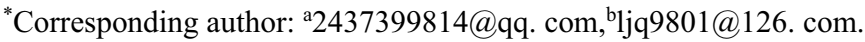




\section{Analysis of the cost of backyard hog production and scale hog production}

\subsection{Cost analysis}

From the cost perspective (Figure1), the average total cost per pig of different scale hog production patterns have shown a significant upward trend from 2007 to 2018 in China. The cost per pig of backyard hog production increased from RMB 1,059.57 in 2007 to RMB 1,872.97 in 2018, an increase of RMB 814. 40, with an average annual growth rate of $5.32 \%$. The cost per pig of small-scale hog production increased from RMB 998.84 in 2007 to RMB 1,641.20 in 2018, an increase of RMB 642.36, with an average annual growth rate of $4.62 \%$. The cost per pig of medium-scale hog production increased from RMB 1,003.24 in 2007 to RMB 1,582.85 in 2018, an increase of RMB 579.61, with an average annual growth rate of $4.23 \%$. The cost per pig of large-scale hog production increased from RMB 999.36 in 2007 to RMB 1,530.64 in 2018, an increase of RMB 531.28, with an average annual growth rate of $3.95 \%$. By comparison, from 2007 to 2018 , the cost per pig of backyard hog production was the highest, and the growth rate was also the fastest. The cost gap between backyard hog production and scale hog production is obviously widening. The cost per pig of small-scale, medium-scale, and large-scale hog production decreases sequentially, and the growth rate slows down sequentially. This shows that with the expansion of production scale, production costs will gradually decrease, and scale hog production has obvious cost advantages over backyard hog production.

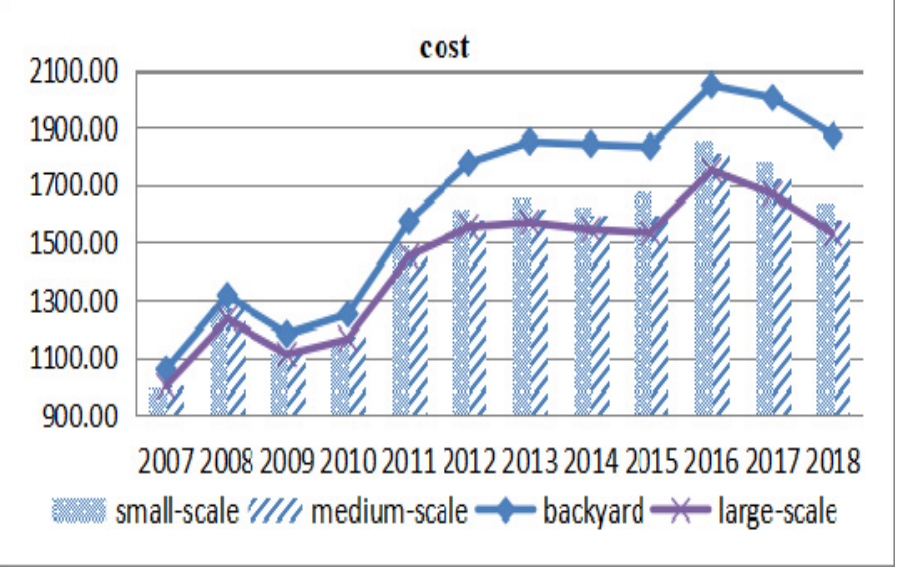

Figure1 The cost per pig of backyard hog production and scale hog production from 2007 to 2018 in China (The data comes from the "Compilation of National Agricultural Product Cost and Benefit Information")

\subsection{Cost structure analysis}

From the perspective of cost structure (Figure2), from 2007 to 2018, the main incentives for the high cost of backyard hog production in China was the high input of piglets, feed and labor, which accounted for $25.73 \%$, $48.89 \%$, and $22.11 \%$ of the total cost, respectively. The main incentives for the cost of scale pig production was the high input of piglets and feed. Small-scale, mediumscale, and large-scale piglet costs and feed costs account for more than $80 \%$ of the total cost. With the expansion of the scale of pig production, the proportion of piglet costs gradually increased from $25.73 \%$ to $33.73 \%$. The proportion of feed costs first increased and then decreased, with the largest being medium-scale(56.48\%). The proportion of labor costs gradually decreased from $22.11 \%$ to $5.86 \%$, and the proportion of other costs gradually increased from $3.28 \%$ to $5.92 \%$. It shows that scale pig production pays more attention to the selection of breeding pigs than free-range breeding, and it saves labor costs better.

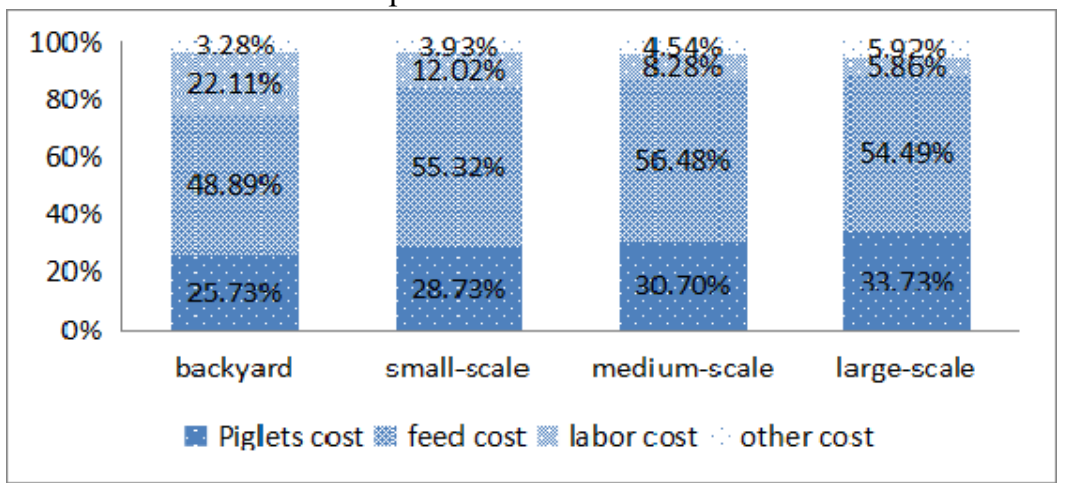

Figure2 Changes in the cost structure of backyard hog production and scale hog production from 2007 to 2018 in China (The data is calculated based on the "Compilation of National Agricultural Product Cost and Benefit Information") 


\section{Analysis of profit from backyard hog production and scale hog production}

\subsection{Output value analysis}

From the perspective of output value (Figure3), the average output value per pig of different scale hog production patterns have shown an upward trend of volatility from 2007 to 2018 in China. The output value per pig of backyard hog production increased from RMB $1,473.66$ in 2007 to RMB $1,637.45$ in 2018 , an increase of RMB 163.79, with an average annual growth rate of
$0.96 \%$. The output value per pig of small-scale hog production increased from RMB $1,380.48$ in 2007 to RMB 1,596.02 in 2018, an increase of RMB 215.54, with an average annual growth rate of $1.33 \%$. The output value per pig of medium-scale hog production increased from RMB 1,392.89 in 2007 to RMB 1,614.83 in 2018, an increase of RMB 221. 94, with an average annual growth rate of $1.35 \%$. The output value per pig of largescale hog production increased from RMB 1,350.44 in 2007 to RMB 1574.60 in 2018, an increase of RMB 224. 16 , with an average annual growth rate of $1.41 \%$. By comparison, the output value per pig of backyard hog production is slightly higher than that of scale hog production, but the growth rate is lower.

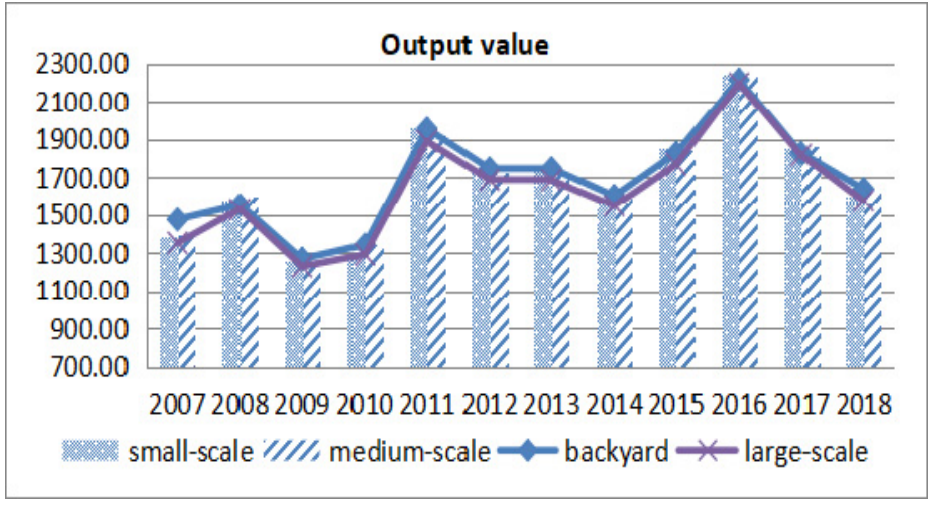

Figure3 The output value per pig of backyard hog production and scale hog production from 2007 to 2018 in China (The data comes from the "Compilation of National Agricultural Product Cost and Benefit Information")

\subsection{Net profit analysis}

From the perspective of net profit (Figure4), the average net profit per pig of different scale hog production patterns have shown an upward trend of volatility from 2007 to 2018 in China, and there are great differences from year to year. The net profit per pig of backyard hog production decreased from RMB 415.09 in 2007 to minus RMB 235.52 in 2018, a decrease of RMB 163. 79. The net profit per pig of small-scale hog production decreased from RMB 381. 64 in 2007 to minus RMB 45.18 in 2018, a decrease of RMB 426.82. The net profit per pig of medium-scale hog production decreased from RMB 389. 65 in 2007 to RMB 31.98 in 2018 , a decrease of RMB 357.67. The net profit per pig of large-scale hog production decreased from RMB 351. 08 in 2007 to RMB 43. 96 in 2018, a decrease of RMB 307.12. On the whole, the average net profit of backyard hog production, small-scale, medium-scale, and large-scale hog production was RMB 47.06, RMB 179.59, RMB 213.77and RMB 202.89, respectively. By comparison, large-scale hog production has always been profitable, medium-scale hog production only suffered losses in 2014, small-scale hog production only suffered losses in 2014 and 2018, and backyard hog production suffered more losses. The net profit of backyard hog production is obviously lower than that of scale hog production, and this profit gap is gradually expanding.

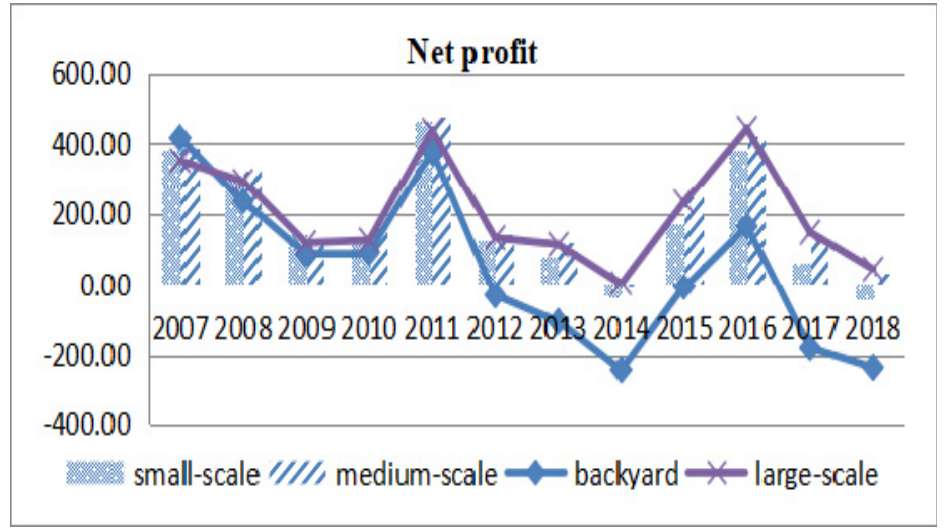

Figure4 The net profit per pig of backyard hog production and scale hog production from 2007 to 2018 in China (The data comes from the "Compilation of National Agricultural Product Cost and Benefit Information") 


\section{Conclusions and recommendations}

\subsection{Conclusion}

Based on cost-benefit indicators, this paper makes a comprehensive comparison between backyard hog production and small, medium and large scale production, clarifies the development status and differences of backyard hog production and scale hog production, and puts forward corresponding policy recommendations. The research concluded as follows: (1) the cost of backyard hog production is the highest, and the cost of large-scale production is the lowest, and the cost is inversely proportional to the scale of production; (2) The main incentives for the high cost of backyard hog production are the input of piglets, feed and labor, and The main incentives for the high cost of scale hog production are the input of piglets and feed. Scale hog production saves labor costs more than backyard hog production; (3) The net profit of backyard hog production is the lowest, and the net profit of medium-scale production is the highest. It is not that the larger the scale, the higher the profit; (4) The profit gap between backyard hog production and scale hog production is gradually expanding, and the economic advantages of scale hog production are obvious. In conclusion, the cost and profit of backyard hog production in China are obviously inferior to scale hog production, and the gap between them is increasing.

\subsection{Policy recommendations}

In view of the above research conclusions, this paper puts forward the following suggestions: (1) Improve the breeding technology service system to improve the production efficiency of farmers. Improve the technical service system of pig breeding through on-site guidance, opening training courses, etc. and promote the combination of "extensive + precise" breeding to improve farming efficiency. (2) Develop moderately large-scale breeding to improve the economic benefits of farmers. Considering the constraints of resources, environment and technology, rely on government financial subsidies and technology promotion to encourage capable farmers to develop in the direction of moderate scale aquaculture, so as to reduce their production costs, strengthen professional aquaculture, and improve the economy of farmers income. (3) Improve the level of organization of farmers and build a mechanism for linking interests. Take leading enterprises and specialized cooperatives as important organizational carriers and give full play to their leading role. Establish a business model of "enterprise (cooperative) + farmer + market" to improve the organization and standardization of farmer households, realize the sharing of benefits and risks among economic entities in the pig industry chain, and gradually reverse the disadvantaged position of farmers.

\section{Fund Project:}

Sichuan Provincial Social Science Project "Study on the Status Quo and Influencing Factors of Agricultural Highquality Development in Sichuan Province" (SC19B084)

\section{References}

1. Song Lianxi. Analysis of pros and cons and trend prediction of the backyard hog production model[J]. Chinese Journal of Animal Husbandry, 2007, 43(018):17-20.

2. Qiao, FB, Chen, J. , Carter, C. , Huang, JK, Rozelle, S. Market Development and the Rise and Fall of Backyard Hog Production in China. The Developing Economies ,2011,(2): 203 -222.

3. Chen Rong, Ouyang Xi. The characteristics and reasons analysis of the withdrawal of scatteredraising households under the structural changes of the pig industry_-Based on the survey of 274 farmers in Leshan City, Sichuan Province[J]. China Journal of Animal Husbandry, 2015(16): 34 -38.

4. Liu Chunming, Hao Qingsheng, Zhou Yang. Research on the cost efficiency and influencing factors of free-range dairy cattle breeding in my country $[\mathrm{J}]$. China Animal Husbandry and Veterinary Medicine, 2018, 054(011):123-127.

5. Zhou Jing, Chen Yuping, Ding Shijun. The impact of the "package" subsidy policy on the large-scale process of China's pig breeding_Estimation based on the double difference method[J]. China Rural Economy, 2015, 000(004): 29-43 .

6. $\mathrm{Hu}$ Xiaoping, Gao Hongyang. Analysis of the cause of the trend of large-scale pig breeding in my country[J]. Journal of Sichuan Normal University (Social Science Edition), 2015, v. 42; No. 213(006):38-44.

7. Zhou Yang, Hao Qingsheng. Research on the efficiency of free-range pig breeding and its influencing factors in my country under the new economic normal $[\mathrm{J}]$. Heilongjiang Animal Husbandry and Veterinary Medicine, 2018(18): 3438.

8. Yang Yimin, Luo Xiaowen. Analysis of willingness to cooperate with pig farmers in professional farmer cooperatives_-Based on the survey data of the pig industry in Hunan Province[J]. Heilongjiang Animal Husbandry and Veterinary Medicine, 2016(16): 2326.

9. Ji Chen, Jia Fu, Xu Xuchu. Analysis on the Growth of Farmer Cooperatives from the Perspective of Rebalancing and Performance-Analysis of Multiple Cases of Pig Breeding Cooperatives[J]. China Rural Observation, 2017(03): 72-86 .

10. Hu Kai, Gan Xiaoqing. Research on the optimal breeding scale of farmers in the pig supply chain of the "company + farmers" model[J]. System Engineering Theory and Practice, 2013, 33(5):12001206. 
11. Zhang Xiaoheng, Zhou Yingheng, Zhang Peng. Estimation of the environmental efficiency of pig breeding in China: Taking the surplus of nitrogen in manure as an example[J]. Agricultural Technology Economy, 2015(05): 92-102.

12. Wang Gangyi, Lu Fengjun, Shan Fubin. Price-based revenue sharing game analysis: Taking the order-led health pig farming industry chain organization model as an example [J]. Exploration of Economic Issues, 2011(06): 88-92 .

13. Xu Biao, Shi Liang, Liu Yang. Research on the large-scale evolution model of the pig breeding industry in my country $[\mathrm{J}]$. Issues of Agricultural Economics, 2015(2): 21-26. 